\title{
Contralateral breast cancer risk in relation to tumor morphology and age-in which patients is preoperative MRI justified?
}

\author{
N. A. de Glas $\cdot$ C. C. Engels $\cdot$ E. Bastiaannet $\cdot$ W. van de Water $\cdot$ S. Siesling $\cdot$ \\ A. J. M. de Craen · C. J. H. van de Velde · G. J. Liefers · J. W. S. Merkus
}

Received: 9 July 2014 / Accepted: 2 February 2015 / Published online: 13 February 2015

(c) The Author(s) 2015. This article is published with open access at Springerlink.com

\begin{abstract}
Identification of patients who are at increased risk for contralateral breast cancer is essential to determine which patients should be routinely screened for contralateral breast cancer using MRI. The aim of this study was to assess the association of age and tumor morphology with contralateral breast cancer incidence in a large, nationwide population-based study in the Netherlands. All patients with breast cancer stage I-III, diagnosed between 1989 and 2009, were selected from the Netherlands Cancer Registry. The association between contralateral breast cancer risk with tumor morphology and age was assessed using competing-risk regression according to Fine \& Gray. Overall, 194,898 patients were included. In multivariable analyses,
\end{abstract}

N. A. de Glas and C. C. Engels have contributed equally to this work.

Electronic supplementary material The online version of this article (doi:10.1007/s10549-015-3294-6) contains supplementary material, which is available to authorized users.

N. A. de Glas $(\bowtie)$. C. C. Engels · E. Bastiaannet .

W. van de Water - C. J. H. van de Velde - G. J. Liefers

Department of Surgery, Leiden University Medical Center,

P.O. Box 9600, Postzone K6-R, 2300 RC Leiden,

The Netherlands

e-mail: n.a.de_glas@lumc.nl

G. J. Liefers

e-mail: g.j.liefers@lumc.nl

E. Bastiaannet · W. van de Water - A. J. M. de Craen Department of Gerontology \& Geriatrics, Leiden University

Medical Center, Leiden, The Netherlands

S. Siesling

Netherlands Cancer Registry, Utrecht, The Netherlands

J. W. S. Merkus

Department of Surgery, HAGA Hospital, The Hague,

The Netherlands lobular tumors were significantly associated with an increased risk of contralateral breast cancer within 6 months (cumulative incidence $1.9 \%$, subdistribution hazard ratio (SHR) 1.17, $95 \%$ confidence interval (CI) 1.06-1.30 compared with $1.3 \%$ in ductal tumors, $p=0.002$ ). Age was also associated with an increased risk of contralateral breast cancer within 6 months (SHR 2.34, $95 \%$ CI $2.08-2.62, p<0.002$ for patients over the age of 75 as compared to patients younger than 50 years). The absolute risk of contralateral breast cancer within 6 months is only slightly increased in patients with a lobular tumor and older patients. In our view, this small increased risk does not justify standard use of preoperative MRI based on tumor morphology or age alone. We propose a more personalized strategy in which additional risk factors (family history, prognosis of primary tumor, and others) may play a role.

Keywords Breast cancer - Contralateral breast cancer . Lobular carcinoma $\cdot$ Older patients · Epidemiology

\section{Introduction}

Breast cancer incidence rates are increasing [1, 2], and consequently, an increased number of patients are at risk for developing contralateral breast cancer [3]. In general, incidence rates for contralateral breast cancer after primary breast cancer of approximately $1 \%$ per year have been reported [4]. Several studies have shown that survival after contralateral breast cancer is impaired compared to patients with unilateral breast cancer [3, 5-7]. Therefore, identification of patients who are at increased risk for contralateral breast cancer is essential in order to determine which patients should be routinely screened for contralateral breast cancer using magnetic resonance imaging (MRI). Due to 
the high costs, the use of MRI should be limited to the patients in which the risk of contralateral breast cancer is the highest.

Currently, the Dutch breast cancer guideline recommends to perform a preoperative MRI in all patients with invasive lobular breast cancer, unless an unifocal mass is observed on a mammogram that is properly assessable [8]. Invasive lobular carcinoma is one of the previously described risk factors for contralateral breast. Invasive lobular carcinoma is characterized by a particular single-file growth pattern, tends to be larger at diagnosis, estrogen (ER) and progesterone receptor (PR) positive, more likely to occur in the older patient and less aggressive than their ductal counterparts $[9,10]$.

Also, several previous studies have shown that the risk of contralateral breast cancer within 6 months after the initial diagnosis increases with age [3], while the risk of contralateral breast cancer during follow-up is the highest in younger patients $[4,5]$. However, the Dutch breast cancer guideline states that MRI is not of additional value in women aged 70 years or older, even though the incidence of breast cancer increases with age [8].

With the increasing health expenditure of recent years [11], we question if the standard MRI that is currently performed in patients with a lobular tumor as well as the omission of MRI in older patients can be justified.

Therefore, we aimed at assessing the association of age and tumor morphology with contralateral breast cancer incidence within 6 months after diagnosis in a large, nationwide population-based study in the Netherlands. In addition, we assessed the association of these factors with the risk of contralateral breast cancer after 6 months.

\section{Methods}

\section{Study population}

Patients were selected from the Netherlands Cancer Registry. After notification by the nationwide Dutch network and registry of histo- and cytopathology (PALGA) and the national hospital discharge databank, trained registry personnel collected data on diagnosis, staging, and treatment using the registration and coding manual of the Comprehensive Cancer Center the Netherlands. Female patients diagnosed between 1989 and 2009 who received surgery for their first primary breast cancer stage I-III were selected from the Dutch Cancer Registry. Based on a unique patient number, second primary breast cancers were linked to each individual patient. All second primary cancers that occurred in the contralateral breast after the initial diagnosis were included. Patients with unknown localizations of the breast cancer were excluded as it could not be recalled if the second primary tumor was localized in the contralateral breast $(n=51)$.

Statistical analysis

The date of the first breast cancer diagnosis was defined as the date of pathological diagnosis (usually via biopsy). As it is unlikely that a new contralateral breast cancer occurs within 6 months after the initial diagnosis, a division was made according to previous literature $[3,5,6]$ into contralateral breast cancer within 6 months and after 6 months (following the index cancer). We thereby assumed that any tumor that occurred within 6 months after the initial diagnosis was in fact a bilateral tumor. If patients presented with bilateral breast cancer at first diagnosis, they were included, and follow-up between the initial diagnosis and the contralateral breast cancer was defined as 0.00001 days in order to be able to include these patients in the Fine \& Gray analyses.

Differences between patient groups were assessed using Chi-square tests. Age was divided into $<50,50-64,65-74$ and 75 years and older. Histological grade was defined as Grade I, Grade II, or Grade III. Morphology was defined as ductal, lobular, or other. ER and PR-status were registered by the Netherlands Cancer Registry starting from the year 2005, and defined as negative, positive, or unknown. Pathological T-stage and N-stage according to the TNMclassification that was applicable in the year of diagnosis were used. If pathological stage was missing, clinical stage was used. T-stage was categorized as stage I, II, III, IV, or "unknown", and N-stage was analyzed as N0, N1, N2, N3, or unknown.

Since the occurrence of contralateral breast cancer may be influenced by the risk of competing endpoints (defined as death without contralateral breast cancer) [12], the cumulative incidences of contralateral breast cancer can be overestimated when regular analyses such as the KaplanMeier Method or the Cox Regression model are used. Therefore, all cumulative incidences were estimated by competing-risks regression according to Fine \& Gray to assess the risk of a contralateral breast cancer while taking into account the risks of reaching other, competing endpoints [13]. Cumulative incidences were calculated for the total cohort and stratified according to lobular and ductal breast cancer and age. Additionally, the differences in cumulative incidence rates between lobular and ductal breast cancer were further stratified in periods to study changes over time. Contralateral breast cancer after 6 months was assessed using the time between 6 months after diagnosis and occurrence of contralateral breast cancer or end of follow-up, with death from any cause as competing event. Patients who had a contralateral breast cancer within 6 months were excluded from these analyses. 
First, we performed univariate competing-risks regression, in which all variables as described above were evaluated. Second, all variables were entered in the multivariable model (full model).

\section{Results}

Patient population

Overall, 194,898 patients with breast cancer stage I-III who received surgical treatment were included (Table 1).

Table 1 Characteristics of the population female breast cancer patients, stage I-III (who received surgery) and known localization

\begin{tabular}{|c|c|c|}
\hline & Number & $\%$ \\
\hline \multicolumn{3}{|l|}{ Period } \\
\hline 1989-1998 & 81,549 & 41.8 \\
\hline 1999-2009 & 113,349 & 58.2 \\
\hline \multicolumn{3}{|l|}{ Age } \\
\hline$<50$ & 51,481 & 26.4 \\
\hline $50-64$ & 72,375 & 37.1 \\
\hline $65-74$ & 41,375 & 21.3 \\
\hline $75+$ & 29,667 & 15.2 \\
\hline \multicolumn{3}{|l|}{ Grade } \\
\hline I & 25,316 & 13.0 \\
\hline II & 58,681 & 30.1 \\
\hline III & 52,337 & 26.9 \\
\hline Unknown & 58,564 & 30.0 \\
\hline \multicolumn{3}{|l|}{ Morphology } \\
\hline Ductal & 145,777 & 74.8 \\
\hline Lobular & 21,560 & 11.1 \\
\hline Unknown & 27,561 & 14.1 \\
\hline \multicolumn{3}{|l|}{ T-stage } \\
\hline I & 108,724 & 55.8 \\
\hline II & 70,733 & 36.3 \\
\hline III & 7,108 & 3.6 \\
\hline IV & 6,020 & 3.1 \\
\hline Unknown & 2,313 & 1.2 \\
\hline \multicolumn{3}{|l|}{ Nodal stage } \\
\hline N0 & 116,559 & 59.8 \\
\hline N1 & 66,067 & 33.9 \\
\hline $\mathrm{N} 2$ & 6,643 & 3.4 \\
\hline N3 & 3,219 & 1.7 \\
\hline Unknown & 2,410 & 1.2 \\
\hline \multicolumn{3}{|l|}{ Localization* } \\
\hline Left & 100,932 & 51.8 \\
\hline Right & 93,966 & 48.2 \\
\hline Total & 194,898 & 100 \\
\hline
\end{tabular}

* Localization unknown in 51 patients (excluded)
Follow-up was complete until December 31st, 2010. Median follow-up was 6.2 years (range 0-21.0 years).

Around seventy five percent of the patients in this cohort were diagnosed with breast cancer of ductal morphology, lobular morphology was seen in $11 \%$ of the patients and in $14 \%$ the morphology was unknown (Table 1). Twenty six percent of the patients in this cohort were younger than 50 years of age, $37 \%$ of the patients ranged between 50 and 64 years and $37 \%$ was older than 65 years (Table 1). The cumulative incidence of contralateral breast cancer within 6 months was $1.4 \%$ (2,829 cases), while the cumulative incidence of contralateral breast cancer after 6 months was $3.7 \%(7,185$ cases) at the end of follow-up (Table 2).

Patient and tumor characteristics in relation to contralateral breast cancer

Patients with high (pathological) T-stage and N-stage were more likely to be diagnosed with contralateral breast cancer within 6 months. The incidence of contralateral breast cancer was lower in ER-receptor negative patients compared to ER-receptor positive patients (Table 2).

The cumulative incidence of contralateral breast cancer within 6 months was higher with increasing age, while the incidence of contralateral breast cancer after 6 months was lower in the older patients (Table 2; Fig. 1). Lobular tumors were more often associated with contralateral breast cancer within and after 6 months $(1.9 \%$ of patients with lobular morphology developed contralateral breast cancer within 6 months versus $1.3 \%$ of patients with ductal morphology (Fig. 2) and $4.1 \%$ of patients with lobular morphology developed contralateral breast cancer after 6 months versus $3.5 \%$ of patients with ductal morphology $(p<0.001$, Fig. 3).

The incidence of contralateral breast cancer within 6 months did not change in previous years, but the incidence of contralateral breast cancer after 6 months decreased from $6.2 \%$ in patients who were diagnosed between 1989 and 1995 to $1.3 \%$ in patients who were diagnosed between 2003 and 2009 (Table 2). In order to assess if this change was explained by a difference in length of follow-up, we performed additional sensitivity analyses in which we truncated the follow-up. These analyses showed that indeed, the observed decrease in CBC was mostly explained by a difference in length of follow-up, as the difference in contralateral breast cancer at 3 years and 5 years did not significantly differ between the three time periods (Attachment 1).

Competing risk analyses

In Table 3, we assessed the risk of contralateral breast cancer while taking the risk of competing endpoints into account, as these competing endpoints may influence the 
Table 2 Patient characteristics in relation to unilateral and contralateral breast cancer

\begin{tabular}{|c|c|c|c|c|}
\hline \multirow{2}{*}{$\begin{array}{l}\text { Table } 2 \text { Patient characteristics } \\
\text { in relation to unilateral and } \\
\text { contralateral breast cancer }\end{array}$} & & \multicolumn{3}{|c|}{ Contralateral breast cancer } \\
\hline & & $\begin{array}{l}\text { UBC } \\
n=184,884(94.9 \%)\end{array}$ & $\begin{array}{l}\mathrm{CBC} \leq 6 \text { months } \\
n=2829(1.4 \%)\end{array}$ & $\begin{array}{l}\text { CBC }>6 \text { months } \\
n=7,185(3.7 \%)\end{array}$ \\
\hline & Age & $\mathrm{N}(\%)$ & $\mathrm{N}(\%)$ & $\mathrm{N}(\%)$ \\
\hline & $<50$ & $48,743(94.7)$ & $506(1.0)$ & $2,232(4.3)$ \\
\hline & $50-64$ & $68,716(94.9)$ & $909(1.3)$ & $2,750(3.8)$ \\
\hline & $65-74$ & $39,171(94.7)$ & $683(1.6)$ & $1,521(3.7)$ \\
\hline & $75+$ & $28,254(95.2)$ & $731(2.5)$ & $682(2.3)$ \\
\hline & \multicolumn{4}{|l|}{ Period } \\
\hline & 1989-1995 & $51,018(92.4)$ & 799 (1.4) & $3,413(6.2)$ \\
\hline & $1996-2002$ & $62,211(94.3)$ & $939(1.4)$ & $2,824(4.3)$ \\
\hline & 2003-2009 & $71,655(97.2)$ & $1,091(1.5)$ & $948(1.3)$ \\
\hline & \multicolumn{4}{|l|}{ Morphology } \\
\hline & Ductal & $138,801(95.2)$ & $1,940(1.3)$ & $5,036(3.5)$ \\
\hline & Lobular & $20,254(94.0)$ & $416(1.9)$ & $890(4.1)$ \\
\hline & Unknown & $25,829(93.7)$ & $473(1.7)$ & $1,259(4.6)$ \\
\hline & \multicolumn{4}{|l|}{ T-stage } \\
\hline & I & $103,115(94.8)$ & $1,377(1.3)$ & $4,232(3.9)$ \\
\hline & II & $67,261(95.1)$ & $1,129(1.6)$ & $2,343(3.3)$ \\
\hline & III & $6,664(93.8)$ & $144(2.0)$ & $300(4.2)$ \\
\hline & IV & $5,691(94.5)$ & $129(2.2)$ & $200(3.3)$ \\
\hline & Unknown & $2,153(93.1)$ & $50(2.2)$ & $110(4.7)$ \\
\hline & \multicolumn{4}{|l|}{ Nodal stage } \\
\hline & N0 & $110,043(94.4)$ & $1,562(1.3)$ & $4,954(4.3)$ \\
\hline & N1 & $63,009(95.4)$ & $1,050(1.6)$ & $2,008(3.0)$ \\
\hline & $\mathrm{N} 2$ & $6,449(97.1)$ & $98(1.5)$ & $96(1.4)$ \\
\hline & N3 & $3,119(96.9)$ & $52(1.6)$ & $48(1.5)$ \\
\hline & Unknown & 2,264 (93.9) & $67(2.8)$ & $79(3.3)$ \\
\hline & \multicolumn{4}{|l|}{ Grade } \\
\hline & I & $24,145(95.3)$ & $420(1.7)$ & $751(3.0)$ \\
\hline & II & $56,071(95.5)$ & $924(1.6)$ & $1,686(2.9)$ \\
\hline & III & $50,143(95.8)$ & $606(1.2)$ & $1,588(3.0)$ \\
\hline & Unknown & $54,525(93.1)$ & $879(1.5)$ & $3,160(5.4)$ \\
\hline & \multicolumn{4}{|c|}{ Estrogen receptor } \\
\hline & Positive & $21,315(94.3)$ & $338(1.5)$ & $951(4.2)$ \\
\hline & Negative & $3497(95.1)$ & $42(1.1)$ & $140(3.8)$ \\
\hline & Unknown & $160,072(94.9)$ & $2,449(1.5)$ & $6,094(3.6)$ \\
\hline & \multicolumn{4}{|c|}{ Progesterone receptor } \\
\hline & Positive & $15,800(94.3)$ & $250(1.5)$ & $697(4.2)$ \\
\hline$U B C$ unilateral breast cancer, & Negative & $7,962(94.4)$ & 118 (1.4) & $358(4.2)$ \\
\hline $\begin{array}{l}C B C \text { contralateral breast cancer. } \\
\text { For all }\end{array}$ & Unknown & $161,122(94.9)$ & $2,461(1.5)$ & 6,130 (3.6) \\
\hline
\end{tabular}

$U B C$ unilateral breast cancer, $C B C$ contralateral breast cancer. For all variables: $p<0.001$ risk of contralateral breast cancer. In multivariable competing risk analyses, lobular tumors were significantly associated with an increased risk for contralateral breast cancer within 6 months (subdistribution hazard ratio (SHR) $1.17,95 \%$ C.I. 1.06-1.30 compared with ductal tumors, $p=0.002)$ and contralateral breast cancer after 6 months (SHR: 1.19, $95 \%$ C.I. 1.11-1.28 compared with ductal tumors, $p<0.001$ ) (Table 3; Fig. 1). Similarly, increasing age was associated with an increased risk of contralateral breast cancer within 6 months (SHR 2.34, $95 \%$ C I 2.08-2.62, $p<0.001$ for patients 75 and older compared with patients younger than 50 years). Again, the risk of developing contralateral breast cancer after 6 months decreased with increasing age (SHR 0.52, $95 \%$ CI $0.48-0.57, p<0.001$ for patients 75 and older compared with patients younger than 50 years). 


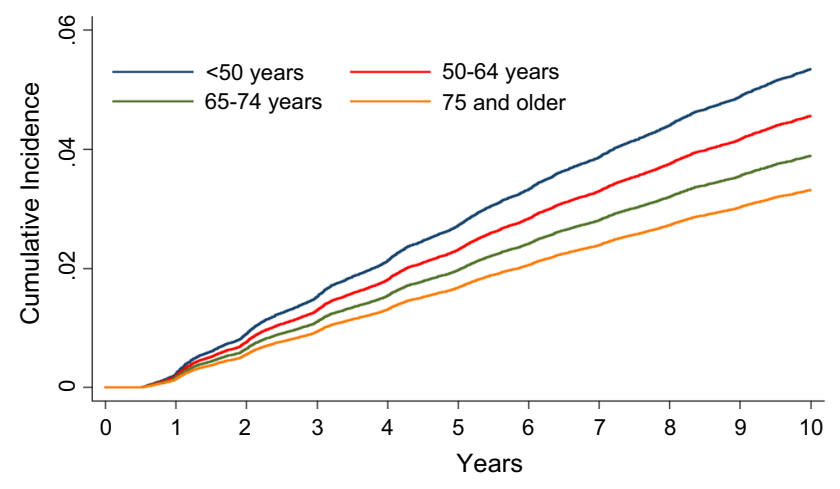

Fig. 1 Cumulative incidence of contralateral breast cancer after 6 months per age-group

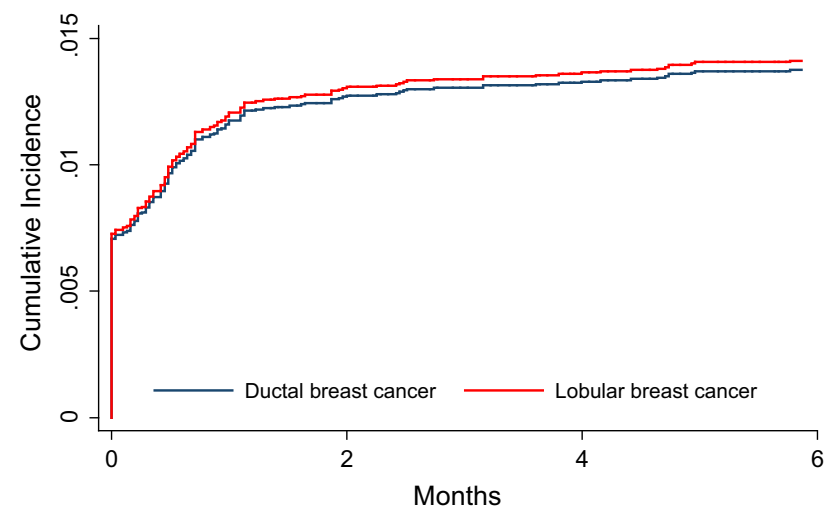

Fig. 2 Cumulative incidence of contralateral breast cancer within 6 months per morphology

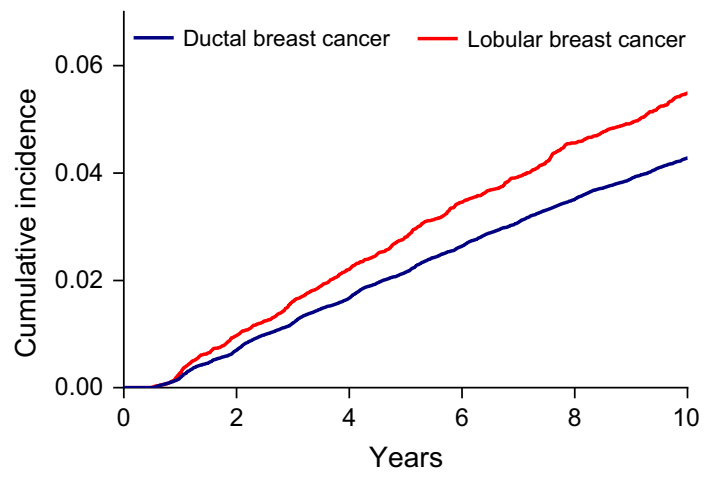

Fig. 3 Cumulative incidence of contralateral breast cancer after 6 monthx per morphology

Stratified by age, lobular morphology remained significantly associated with risk of contralateral breast cancer within 6 months in patients aged 64 years or younger ( $<50$ years: SHR 1.37, $95 \%$ C.I. $1.05-1.80, p=0.02$ for lobular tumors compared with ductal tumors; 50-64 years: SHR $1.45,95 \%$ C.I. $1.20-1.74, p<0.001$ for lobular tumors) (Attachment 2). A similar trend was observed for the association between morphology and risk of contralateral breast cancer within 6 months in patients with tumor stages T1 (SHR 1.36, $95 \%$ C.I. 1.15-1.60, $p<0.001$ ) and T2 (SHR 1.22, $95 \%$ C.I $1.0-1.44, p=0.02$ ), while no association between morphology and contralateral breast cancer within 6 months was observed in patients with T3 and T4 tumors. (Attachment 2).

For contralateral breast cancer after 6 months, patients below the age of 50 showed a significant association for tumor morphology, in favor of ductal morphology (SHR $1.37,95 \%$ C.I. $1.20-1.57, p<0.001$ for lobular tumors compared to ductal tumors). Furthermore, patients diagnosed with pathological T1 and T2 stages harboring lobular tumor morphology had a significantly higher risk of contralateral breast cancer after 6 months (T1: SHR 1.13, $95 \%$ C.I. $1.02-1.26, p=0.02$; T2: SHR $1.33,95 \%$ C.I. $1.18-1.50, p<0.001$ ), while tumor morphology was not significantly associated with risk of contralateral breast cancer after 6 months in patients with tumor stage T3 and T4 (Attachment 2).

\section{Discussion}

This study shows that the incidence of contralateral breast cancer, both within and after 6 months, is the highest in patients with lobular tumor morphology, although the absolute risk difference between ductal and lobular tumors is small. Older patients are more likely to develop a contralateral breast cancer within 6 months, but less likely to develop a contralateral breast cancer after this time period, as compared to their younger counterparts.

According to the Dutch guideline, all patients with an invasive lobular tumor must receive an MRI, unless a unifocal mass is observed on a mammogram that is properly assessable [8]. We observed an increased risk of contralateral breast cancer in lobular tumors in accordance with previous studies $[3,4,14]$. However, the risk of synchronous contralateral breast cancer was only 1.2 times higher in patients with lobular tumors, while the absolute risk difference was $0.6 \%$. Furthermore, in patients with high tumor stages, lobular morphology was no longer a prognostic factor for developing contralateral breast cancer, which is most likely explained by the fact that these patients are more likely to die from their breast cancer before they had the chance to develop contralateral breast cancer. Since the absolute risk difference between ductal and lobular tumors was small, and MRI is an expensive imaging technique (one MRI costs approximately 368 euros in the Netherlands (486 USD)) [15], we propose that the standard MRI that is currently advised in all patients with invasive lobular tumors seems inappropriate. 
Table 3 Association (competing risk regression with death as competing risk) between morphology and age with CBC

\begin{tabular}{|c|c|c|c|c|c|c|c|c|}
\hline & \multicolumn{4}{|c|}{$\begin{array}{l}\mathrm{CBC} \leq 6 \text { months } \\
\text { Multivariable analyses }\end{array}$} & \multicolumn{4}{|c|}{$\begin{array}{l}\mathrm{CBC}>6 \text { months** } \\
\text { Multivariable analysis }\end{array}$} \\
\hline & $\begin{array}{l}\mathrm{CBC}<6 \\
\text { months } \\
\mathrm{N}(\%)\end{array}$ & $\begin{array}{l}\text { Competing } \\
\text { mortality } \leq 6 \\
\text { months* } \\
\mathrm{N}(\%)\end{array}$ & $\begin{array}{l}\text { SHR } \\
(95 \% \mathrm{CI})\end{array}$ & $p$ value & $\begin{array}{l}\mathrm{CBC}>6 \\
\text { months } \\
\mathrm{N}(\%)\end{array}$ & $\begin{array}{l}\text { Competing } \\
\text { mortality }>6 \\
\text { month s } \\
\mathrm{N}(\%)\end{array}$ & $\begin{array}{l}\text { SHR } \\
(95 \% \mathrm{CI})\end{array}$ & $p$ value \\
\hline \multicolumn{9}{|c|}{ Morphology } \\
\hline Ductal & $1,940(1.3)$ & $2,854(2.0)$ & 1.0 (reference) & 0.002 & $5,036(3.6)$ & $40,867(29.5)$ & 1.0 (reference) & $<0.001$ \\
\hline Lobular & 416 (1.9) & $394(1.8)$ & $1.17(1.06-1.30)$ & & $890(4.4)$ & $6,355(31.2)$ & $1.19(1.11-1.28)$ & \\
\hline \multicolumn{9}{|l|}{ Age } \\
\hline$<50$ & $506(1.0)$ & 409 (7.9) & 1.0 (reference) & $<0.001$ & $2,232(4.3)$ & $10,448(20.3)$ & 1.0 (reference) & $<0.001$ \\
\hline $50-64$ & 909 (1.3) & $679(9.4)$ & 1.29 (1.16-1.44) & & $2,750(3.8)$ & $15,205(21.0)$ & $0.91(0.86-0.97)$ & \\
\hline $65-74$ & $683(1.6)$ & $812(16.5)$ & $1.68(1.50-1.89)$ & & $1,521(3.7)$ & $14,457(34.9)$ & $0.82(0.77-0.88)$ & \\
\hline$\geq 75$ & $731(2.5)$ & $2,027(68.3)$ & $2.34(2.08-2.62)$ & & $682(2.3)$ & $18,577(62.6)$ & $0.52(0.48-0.57)$ & \\
\hline
\end{tabular}

Adjusted for grade, period, T-stage and nodal stage

* Mortality within 6 months

** T0 for follow-up after 6 months, exclusion of patients with $\mathrm{CBC} \leq 6$ months

In addition, the Dutch guideline states that MRI is of limited diagnostic value in patients older than 70 years. However, we observed a two-fold increased risk of contralateral breast cancer within 6 months for patients aged 75 years and older as compared to patients under the age of 50 independent of tumor morphology, even in competing risk regression which takes competing mortality into account. Also, the absolute risk difference between these patient groups was $1.5 \%$, which is even larger than the difference comparing the morphology types. Furthermore, the increased risk for patients aged 75 years and older was observed while the guidelines were applied, which could mean that a group of older patients are in fact underdiagnosed, as they did not receive a standard MRI because of their age. Therefore, the actual risk for contralateral breast cancer within 6 months after the initial diagnosis might be even higher in older patients than these data suggest. Hence, this finding deserves further attention.

Possibly, our findings can be explained by the fact that elderly patients more often present with a higher tumor stage [16], and therefore may have an increased risk of contralateral breast cancer within 6 months as well. Moreover, the risk of breast cancer increases with age [1, 17], which implies that the risk of a second, contralateral breast tumor is also higher in older patients. In contrast, the risk of contralateral breast cancer during follow-up decreased with age, in accordance with several previous studies $[3,5]$. This may be explained by the large proportion of competing mortality in older patients.

Older breast cancer patients comprise a vulnerable group, as high age is associated with comorbidity and impaired physical function [18, 19]. Consequently, older patients are treated according to guidelines less often [20], and breast cancer mortality in older patients is high, even though the majority of deaths in older breast cancer patients occurs from competing events [21]. Moreover, breast cancer survival of older patients has not improved in recent years, while the survival of younger patients has significantly improved [22], thereby increasing the survival gap between old and young breast cancer patients. Possibly, the increased incidence of contralateral breast cancer in this older population could explain part of the survival difference between young and older patients, as contralateral breast cancer is associated with decreased breast cancer survival $[3,5]$.

This leads to the question: should we routinely screen older patients for clinically and radiologically occult contralateral breast cancer? One could argue that as we have shown that older breast cancer patients are at increased risk of developing contralateral breast cancer within 6 months, it might be an option to screen for contralateral breast cancer in all older breast cancer patients. On the other hand, this can be time-consuming and expensive, especially if techniques such as MRI are used, and the "number needed to MRI" is still rather high. Especially in older patients with multiple comorbidities, the added value of preoperative screening for contralateral breast cancer might be small, as the remaining life expectancy may be smaller than the time to development of contralateral breast cancer or breast cancer death. Also, mammography may be sufficient for preoperative screening in older patients, as breast density decreases with age. Hence, future studies should investigate the value and cost-effectiveness of preoperative MRI in older breast cancer patients. We propose that 
preoperative MRI should be used on a more personalized basis based on tumor characteristics, remaining life expectancy, and patient's preferences.

\section{Strengths and weaknesses}

The main strength of this study was the use of a large population-based database that was derived from the Netherlands Cancer Registry, as it comprises well-registered data of a large number of patients. Furthermore, to our knowledge this study is the first one that used competing risk analyses according to Fine and Gray, which is a major strength of the analyses as we have shown that competing risk plays an important role when investigating risk factors for contralateral breast cancer, especially in older patients. Previous studies that investigated risk factors for contralateral breast cancer generally used Cox proportional hazard models. However, several factors which can be associated with contralateral breast cancer, such as high disease stage [3] and high age, can also lead to a high mortality and therefore to a large proportion of competing events. Therefore, we propose that analyses investigating risk factors for contralateral breast cancer, should always be performed in analyses that take these competing events into account.

Of course, this study is also to some extend limited. Importantly, we depended on the reports of individual pathologists to determine if a tumor was classified as contralateral breast cancer or recurrence. Only tumors that were classified as contralateral breast cancer by the pathologist were registered by the Cancer Registry as such, which may lead to heterogeneity in the definition of contralateral breast cancer. Also, the Netherlands Cancer Registry does not register comorbid diseases, therefore we could not adjust for this in multivariable competing risk analyses. Furthermore, the absence of detailed data on adjuvant treatment limits the analyses. Improvements in adjuvant therapy may partly explain the observed decrease in contralateral breast cancer in most recent years, although this may also be explained by the limited length of followup. Finally, it must be kept in mind that the incidence rates of contralateral breast cancer were (mostly) observed in an era were the guidelines were applied, which means that they may have influenced the observed incidence rates. The first multidisciplinary guideline from 2002 stated that "regular follow-up using mammography" should be performed in patients with lobular carcinoma [23]. The 2008 guideline that is currently used advices pre-operative MRI [8], and it is likely that this method has been gradually adopted between 2002 and 2008. However, if this would have affected the observed incidence rates, it would have resulted in an increase of contralateral breast cancer. Since we did not observe this increase, it is unlikely that it has strongly influenced our analyses.
In conclusion, the absolute risk of contralateral breast cancer within 6 months is low in patients with ductal as well as lobular breast cancer, although patients with lobular tumors were at a slightly increased risk of contralateral breast cancer. Furthermore, increasing age was associated with a high risk of contralateral breast cancer within 6 months, while the risk of contralateral breast cancer after 6 months decreased with increasing age. We propose that the current guidelines should not advice to perform a standard MRI in all patients with lobular breast cancer, as the benefits do probably not outweigh the costs. Instead, preoperative MRI should be used on a more personalized basis based on tumor characteristics, remaining life expectancy, and patient's preferences.

Acknowledgments The authors thank the registration teams of the Comprehensive Cancer Centres for the collection of data for the Netherlands Cancer Registry and the scientific staff of the Netherlands Cancer Registry.

Conflict of interest All authors declare that they have no conflicts of interest. This research did not receive any specific Grant from any funding agency.

Open Access This article is distributed under the terms of the Creative Commons Attribution Noncommercial License which permits any noncommercial use, distribution, and reproduction in any medium, provided the original author(s) and the source are credited.

\section{References}

1. DeSantis C, Siegel R, Bandi P, Jemal A (2011) Breast cancer statistics, 2011. CA Cancer J Clin 61:409-418

2. Netherlands Cancer Registry: Breast Cancer Incidence Rates in the Netherlands; 2011

3. Schaapveld M, Visser O, Louwman WJ, Willemse PH, de Vries EG, van der Graaf WT, Otter R, Coebergh JW, van Leeuwen FE (2008) The impact of adjuvant therapy on contralateral breast cancer risk and the prognostic significance of contralateral breast cancer: a population based study in the Netherlands. Breast Cancer Res Treat 110:189-197

4. Broet P, de la Rochefordiere A, Scholl SM, Fourquet A, Mosseri V, Durand JC, Pouillart P, Asselain B (1995) Contralateral breast cancer: annual incidence and risk parameters. J Clin Oncol 13:1578-1583

5. Vichapat V, Garmo H, Holmqvist M, Liljegren G, Warnberg F, Lambe M, Fornander T, Adolfsson J, Luchtenborg M, Holmberg L (2012) Tumor stage affects risk and prognosis of contralateral breast cancer: results from a large Swedish-population-based study. J Clin Oncol 30:3478-3485

6. Font-Gonzalez A, Liu L, Voogd AC, Schmidt MK, Roukema JA, Coebergh JW, de Vries E, Soerjomataram I (2013) Inferior survival for young patients with contralateral compared to unilateral breast cancer: a nationwide population-based study in the Netherlands. Breast Cancer Res Treat 139:811-819

7. Heron DE, Komarnicky LT, Hyslop T, Schwartz GF, Mansfield CM (2000) Bilateral breast carcinoma: risk factors and outcomes for patients with synchronous and metachronous disease. Cancer 88:2739-2750

8. NABON: Richtlijn Mammacarcinoom versie 2.0; 2012 
9. Mathieu MC, Rouzier R, Llombart-Cussac A, Sideris L, Koscielny S, Travagli JP, Contesso G, Delaloge S, Spielmann M (2004) The poor responsiveness of infiltrating lobular breast carcinomas to neoadjuvant chemotherapy can be explained by their biological profile. Eur J Cancer 40:342-351

10. Bharat A, Gao F, Margenthaler JA (2009) Tumor characteristics and patient outcomes are similar between invasive lobular and mixed invasive ductal/lobular breast cancers but differ from pure invasive ductal breast cancers. Am J Surg 198:516-519

11. Centraal Bureau voor de Statistiek: Zorgrekeningen; uitgaven (in lopende en constante prijzen) en financiering; 2013

12. Mell LK, Jeong JH, Nichols MA, Polite BN, Weichselbaum RR, Chmura SJ (2010) Predictors of competing mortality in early breast cancer. Cancer 116:5365-5373

13. Putter H, Fiocco M, Geskus RB (2007) Tutorial in biostatistics: competing risks and multi-state models. Stat Med 26:2389-2430

14. Bernstein JL, Thompson WD, Risch N, Holford TR (1992) Risk factors predicting the incidence of second primary breast cancer among women diagnosed with a first primary breast cancer. Am J Epidemiol 136:925-936

15. Saadatmand S, Tilanus-Linthorst MM, Rutgers EJ, Hoogerbrugge N, Oosterwijk JC, Tollenaar RA, Hooning M, Loo CE, Obdeijn IM, Heijnsdijk EA, de Koning HJ (2013) Cost-effectiveness of screening women with familial risk for breast cancer with magnetic resonance imaging. J Natl Cancer Inst 105:1314-1321

16. Bastiaannet E, Liefers GJ, de Craen AJ, Kuppen PJ, van de Water W, Portielje JE, van der Geest LG, Janssen-Heijnen ML, Dekkers OM, van de Velde CJ, Westendorp RG (2010) Breast cancer in elderly compared to younger patients in the Netherlands: stage at diagnosis, treatment and survival in 127,805 unselected patients. Breast Cancer Res Treat 124:801-807

17. Louwman WJ, Vulto JC, Verhoeven RH, Nieuwenhuijzen GA, Coebergh JW, Voogd AC (2007) Clinical epidemiology of breast cancer in the elderly. Eur J Cancer 43:2242-2252
18. Barnett K, Mercer SW, Norbury M, Watt G, Wyke S, Guthrie B (2012) Epidemiology of multimorbidity and implications for health care, research, and medical education: a cross-sectional study. Lancet 380:37-43

19. Braithwaite D, Satariano WA, Sternfeld B, Hiatt RA, Ganz PA, Kerlikowske K, Moore DH, Slattery ML, Tammemagi M, Castillo A, Melisko M, Esserman L, Weltzien EK, Caan BJ (2010) Long-term prognostic role of functional limitations among women with breast cancer. J Natl Cancer Inst 102:1468-1477

20. van de Water W, Bastiaannet E, Dekkers OM, de Craen AJ, Westendorp RG, Voogd AC, van de Velde CJ, Liefers GJ (2012) Adherence to treatment guidelines and survival in patients with earlystage breast cancer by age at diagnosis. Br J Surg 99:813-820

21. van de Water W, Markopoulos C, van de Velde CJ, Seynaeve C, Hasenburg A, Rea D, Putter H, Nortier JW, de Craen AJ, Hille ET, Bastiaannet E, Hadji P, Westendorp RG, Liefers GJ, Jones SE (2012) Association between age at diagnosis and diseasespecific mortality among postmenopausal women with hormone receptor-positive breast cancer. JAMA 307:590-597

22. Bastiaannet E, Portielje JE, van de Velde CJ, de Craen AJ, Van de Velde S, Kuppen PJ, van der Geest LG, Janssen-Heijnen ML, Dekkers OM, Westendorp RG, Liefers GJ (2011) Lack of survival gain for elderly women with breast cancer. Oncologist $16: 415-423$

23. Rutgers EJ, Nortier JW, Tuut MK, van TG, Struikmans H, Bontenbal M, von Meyenfeldt MF, Vreugdenhil G, Benraadt T, Garssen B, Peterse JL (2002) [Dutch Institute for Healthcare Improvement guideline, "Treatment of breast cancer"]. Ned Tijdschr Geneeskd 146:2144-2151 